\title{
Community sentiment following the Deepwater Horizon oil spill disaster: A test of time, systemic community, and corrosive community models
}

Michael R. Cope

Brigham Young University - Provo, michaelrcope@byu.edu

Tim Slack

Louisiana State University

Jorden E. Jackson

Brigham Young University - Provo

Vanessa Parks

University of Mississippi

Follow this and additional works at: https://scholarsarchive.byu.edu/facpub

Part of the Human Ecology Commons, and the Place and Environment Commons

\section{Original Publication Citation}

Michael R. Cope, Tim Slack, Jorden E. Jackson, Vanessa Parks, Community sentiment following the Deepwater Horizon oil spill disaster: A test of time, systemic community, and corrosive community models, Journal of Rural Studies, Volume 74, 2020, Pages 124-132.

\section{BYU ScholarsArchive Citation}

Cope, Michael R.; Slack, Tim; Jackson, Jorden E.; and Parks, Vanessa, "Community sentiment following the Deepwater Horizon oil spill disaster: A test of time, systemic community, and corrosive community models" (2020). Faculty Publications. 3883.

https://scholarsarchive.byu.edu/facpub/3883

This Peer-Reviewed Article is brought to you for free and open access by BYU ScholarsArchive. It has been accepted for inclusion in Faculty Publications by an authorized administrator of BYU ScholarsArchive. For more information, please contact ellen_amatangelo@byu.edu. 


\title{
Community sentiment following the Deepwater Horizon oil spill disaster: A test of time, systemic community, and corrosive community models
}

\author{
Michael R. Cope ${ }^{\mathrm{a}, *}$, Tim Slack ${ }^{\mathrm{b}}$, Jorden E. Jackson ${ }^{\mathrm{a}}$, Vanessa Parks ${ }^{\mathrm{c}}$ \\ ${ }^{\text {a } B r i g h a m ~ Y o u n g ~ U n i v e r s i t y, ~ U S A ~}$ \\ ${ }^{\mathrm{b}}$ Louisiana State University, USA \\ ${ }^{\mathrm{c}}$ University of Mississippi, USA
}

\section{A R T I C L E I N F O}

\section{Keywords:}

Deepwater horizon oil spill

BP oil spill

Recreancy

Disaster

Community

\begin{abstract}
A B S T R A C T
A fundamental concern in the social science scholarship on disasters is understanding community impacts and recovery as a social process. This study examines community sentiment in the aftermath 2010 BP Deepwater Horizon oil spill (DHOS), including the influence of time and the explanatory utility of two major theoretical perspectives - the systemic community model and the corrosive community model—in predicting community sentiment in the context of this disaster. Specifically, our objectives are to assess how community sentiment in the wake of the DHOS: 1) changes over time; 2) is related to the systemic model; and 3) is related to the corrosive model. To meet these objectives, we analyze four waves of data from a unique repeated cross-sectional household survey data—the Louisiana Community Oil Spill Survey (COSS)—collected between 2010 and 2013. Our results demonstrate that 1 ) accounting for other factors, community sentiment community sentiment was significantly greater in later time periods compared to 2010, and 2) the simultaneous and complimentary utility of the systemic and corrosive community frameworks for understanding community sentiment in the wake of the DHOS.
\end{abstract}

\section{Introduction}

A fundamental concern in the social science scholarship on disasters is understanding community impacts and recovery as a social process. An oft-cited definition (Fritz, 1961: 655) acknowledges community implicitly in the concept of disaster: "an event, concentrated in time and space, in which a society, or a relatively self-sufficient subdivision of a society undergoes severe danger and incurs such losses to its members and physical appurtenances that the social structure is disrupted and the fulfillment of all of or some of the essential functions of the society is prevented" (emphasis added). Accordingly, much research focuses on disaster impacts on places, neighborhoods, and towns (Bolin and Kurtz, 2018; Kendra and Wachtendorf, 2007). Moreover, as social processes, the ways in which communities respond to major disruptions can take different trajectories. One regard in which this is true is whether the disaster is viewed as "natural" or "human-made" (Freudenburg, 2000; Gill and Steven Picou, 1998; Gill and Ritchie, 2018; Kroll-Smith and Couch, 1990; Kroll-Smith, 2018; Perry, 2018; Tierney, 2006). In the context of a process viewed as a natural disaster, it is argued that a "therapeutic community" is likely to emerge, as people show a high level of cohesiveness and provide mutual aid in response and recovery efforts. Conversely, the perception that a disaster is generated by a human-made technological failure is said to bring about a community response rife with division and conflict, an outcome that has been called "corrosive community" (Freudenburg, 1993, 1997, 2000).

The purpose of this study is to assess how community sentiment in the wake of a technological disaster: 1) changes over time; 2 ) is related to the systemic model of community (Kasarda and Janowitz, 1974); and 3 ) is related to the corrosive model of community (Freudenburg, 1993, 1997; 2000; Freudenburg and Jones, 1991; Picou et al., 2004). We address these goals by studying community sentiment among coastal residents living in largely rural communities in southeast Louisiana, USA, following the 2010 BP Deepwater Horizon oil spill (DHOS). In doing so, this study helps extend the general social scientific understanding of disasters (e.g., Drabek, 2013; Erikson, 1976, 1994; KrollSmith, 2018; Perry, 2018; Quarantelli, 2005; Quarantelli and Dynes, 1977). More specifically, we contribute to the literature by examining how technological disasters can impact and alter residents' perceptions of an individual experience of community (e.g., Cope et al., 2013; Edelstein, 2004; Gill et al., 2012; Gill and Ritchie, 2018; Kroll-Smith and Couch, 1991; Lee and Blanchard, 2012; McSpirit et al., 2007).

\footnotetext{
* Corresponding author. Department of Sociology, 2008 JFSB Provo, UT, 84602, USA.

E-mail address: michaelrcope@byu.edu (M.R. Cope).
} 


\section{Disaster and community}

While the word community is often idealized because it conjures an image of "a 'warm' place, a cozy and comfortable place ... like the roof under which we shelter in heavy rain, like a fireplace at which we warm our hands on a frosty day" (Bauman, 2001: 1), it also carries fundamental assumptions of feelings "that members have of belonging, a feeling that members matter to one another and to the group, and a shared faith that members' needs will be met through their commitment to be together" (McMillan and Chavis, 1986: 9). In fact, some scholars have theorized community explicitly as moral proximity (e.g., Bauman, 2001; de Tocqueville, 2000 [1840]; Goodsell et al., 2014), while others view it as fundamental to the formation of individual and shared interpretive frameworks and social paradigms-termed "lifescape" by Edelstein (2004)—that underpin everyday assumptions about life.

Conversely, other scholars contend (e.g., Drabek, 2013; Elias and Scotson, 1965; Lindell, 2013; Peacock and Ragsdale, 1997) that the positive "feels good" associations ascribed to community are often reflective of wishful thinking rather than of real social conditions. Such scholars view community as being imbued with conflict as much as it is with consensus, as members with competing interests negotiate for resources and power. Accordingly, as certainty, predictability, and security collapse, contention may arise from an unequal distribution of risk amongst community residents. Such risks are seen as a defining characteristic of contemporary social life and, consequently, controversy and conflict can result as various community members attend to hazards, insecurities, and threats, while others seek to minimize the same issues. Conflicts can intensify following a collective trauma, threaten "the essential functions of society" (Fritz, 1961: 655) and disrupt the typical social order (e.g., Drabek, 2013). Indeed, early social scientific investigations of disasters endeavored to understand just how such disruptions to community occur (e.g., Bucher, 1957; Killian, 1954; Wallace, 1956).

Building on groundbreaking disaster research (e.g., Fritz and Marks, 1954; Moore, 1958; Sjoberg, 1962), a social scientific perspective emerged over time that "disasters" only occur when hazardous events cause people collectively to experience disruption of normal social activities (e.g., Bonanno et al., 2010; Fritz, 1961; Quarantelli, 1989; Quarantelli and Dynes, 1977). For example, Quarantelli (2000: 682) conceptualizes disasters in terms of social processes that occur when "the routines of collective social units are seriously disrupted and when unplanned courses of action have to be undertaken to cope with the crisis" (see also Drabek, 2013; Lindell, 2013; Perry, 2018). Thus, disaster-related outcomes are predicated on 1) preexisting social structures and 2) the significance of these structures for both individual and collective responses (Chhotray and Few, 2012; Picou et al., 2004; Smith, 2006; Smith and Dennis, 2007). Disasters, then, should be viewed as systemic processes "that permeate community social structure, producing social responses that are both emergent and constraining" (Picou et al., 2004: 1495; see also Cope et al., 2018; Dynes, 1974; Kreps, 1989, 1998; Parks et al., 2018).

As a systemic social process, the ways in which disaster victims respond to catastrophic disruption often depend on the Thomasian "definition of the situation." For example, when a disaster catalyst is viewed as natural and beyond human control (i.e., "an act of God"), researchers have found that social, psychological, and economic disruptions are relatively limited in duration (Drabek, 1986; Green, 1996; Quarantelli, 1989). In such contexts, the disaster is viewed as a "consensus-type" crisis (Quarantelli and Dynes, 1977; Aldrich and Kyota, 2017; Aldrich and Meyer, 2015; Reuter and Kaufhold, 2018), and response efforts often bring about a high level of social cohesiveness around recovery and the restoration of 'normalcy' for the victims. ${ }^{1}$ In contrast, other researchers have argued that disasters originating from

\footnotetext{
${ }^{1}$ Importantly, the effort to restore "normal" social conditions often-whether intentionally or not-results in reestablishing preexisting social inequalities (Kroll-Smith, 2018).
}

technological hazards have the potential to "create a far more severe and long-lasting pattern of social, economic, cultural and psychological impacts than do natural ones" (Freudenburg, 1997: 26; see also Riaz et al., 2015). Such long-term impacts are part of a debilitating condition-corrosive community (Freudenburg, 1993, 1997; 2000)—in which the negative effects of the disaster damage the residents' sense of community as the "mortar bonding human communities together" (Erikson, 1994: 239) erodes. Accordingly, research has attended to the linkages between an individual's sense of community and well-being following disaster-related disruptions (e.g., Miles, 2015; Norris et al., 2008). Moreover, studies have demonstrated that positive community attitudes and sentiment are key aspects of disaster resilience and recovery (e.g., Cope et al., 2013). Indeed, research suggests the most effective community change agents and emergency managers will take into account individual and local troubles as they manage an everchanging disaster recovery process (Drabek, 2013). Thus, identifying shifts in community sentiment throughout the disaster process is important for benchmarking different social trajectories.

\section{The systemic community model}

In their seminal article, Kasarda and Janowitz (1974: 331) describe what has become one of the most influential models in the study of "local community attitudes and sentiments." Conceptualizing community "as a complex system of friendship and kinship networks and formal and informal associational ties rooted in family life and on-going socialization processes," the authors proposed a "model of community attachment which [they] call the systemic model (1974, 329, emphasis added). From such a perspective, a local community is viewed as "an ongoing system of social networks into which new generations and new residents are assimilated" (Kasarda and Janowitz 1974, 330). Thus, in the same way scholars conceptualize a disaster as a time-bound process, for Kasarda and Janowitz, the development of community sentiments and bonds is "necessarily a temporal process" in which an individual's length of residence is seen "as the key exogenous factor influencing community behavior and attitudes" (Kasarda and Janowitz 1974, 330).

While the length of residence is a critical component of the systemic community model, Kasarda and Janowitz also focused on local social bonds, lifecycle stage, and social position as principal determinants of people's community attitudes and sentiments. Since its introduction, numerous studies have confirmed the applicability of the systemic community model in understanding these outcomes (e.g., Beggs et al., 1996; Brown, 1993; Cope et al., 2015; Flaherty and Brown, 2010; Gerson et al., 1977; Krannich and Greider, 1990). Furthermore, research in diverse contexts has shown significant linkages between individual well-being and sense of community-a feeling of belonging, closeness, and connection to one's community (e.g., Davidson and Cotter, 1991; Grzeskowiak et al., 2003; Kimweli and Stilwell, 2002; St John et al., 1986), including in the context of technological disasters (Cope et al., 2013; Hawkins and Maurer, 2011; Lee and Blanchard, 2012; Parks et al., 2018).

\section{The corrosive community model}

Inasmuch as local social bonds strengthen community attitudes and sentiments, the disruption of those bonds can also disrupt residents' perceptions of an individual experience of the community (Chhotray and Few, 2012; Edelstein, 2004; Erikson, 1994, 1995; Peacock and Ragsdale, 1997). Thus, community residents incorporate risk assessments and perceptions in such a way that collective uncertainty alters their orientation towards community, so that ontological security and community sentiments corrode (see also Kroll-Smith and Couch, 1993; Lee and Blanchard, 2012; Ritchie et al., 2013). During technological disasters, communities may become conflict-prone, dealing as they must with perceptions of seemingly unending risks and uncertainties regarding both environmental and personal exposure (Adeola and 
Steven Picou, 2014; Erikson, 1994, 1995; Gill, 2007; Kroll-Smith and Couch 1993; Picou et al., 2004). Typifying such processes, following the 1989 Exxon Valdez oil spill in Prince William Sound, Alaska, USA, research shows how the dynamics of uncertainty ultimately culminated in "social responses that draw down reserves of social capital, setting the stage for the emergence of individual and collective trauma, lifestyle and lifescape change, a corrosive community, and secondary trauma" (Ritchie et al., 2013, 658; see also Adeola and Steven Picou, 2014; Aldrich and Meyer, 2015; Gill, 2007; Gill and Ritchie, 2018; Ritchie, 2012; Ritchie and Gill, 2010). Indeed, Picou et al. (2004: 1496) contend that in the wake of catastrophic technological failure "the defining characteristic of the post-disaster phase is the emergence of a corrosive community-that is, a consistent pattern of chronic impacts to individuals and communities." To wit, three interrelated dynamics of technological disasters have been identified as particularly noteworthy in "understanding why corrosive communities emerge and persist" (Picou et al., 2004: 1496; see also Marshall et al., 2003): (1) protracted litigation; (2) mental and physical well-being of community residents; and (3) perceptions of recreancy (i.e., governmental and institutional actors' failure to execute entrusted roles and responsibilities properly). For the purposes of this study we focus on the latter two factors. ${ }^{2}$

With regards to adverse disaster related impacts on mental and physical well-being, research has found that the most commonly observed impacts on the well-being of disaster survivors are depression (e.g., Maguen et al., 2009), post-traumatic stress disorder (PTSD; e.g., Neria et al., 2008), and other anxiety-related disorders (e.g., McFarlane et al., 2009). Moreover, disaster-related life conditions can precipitate negative changes in physical health status (Bonanno et al., 2010; Halpern and Tramontin, 2007). While fatalities and injuries following natural disasters are often common among victims in high impact areas, Marshall et al. (2003: 87) note that in the wake of a technological disaster "the most troubling outcome has to do not with direct loss of life, but the potential for long-term health problems and damage to the community." To the degree that such impacts are chronic and cumulative, and physical symptoms can manifest analogous to other ailments, diagnosis is often delayed because of the difficulty of pinpointing a specific point of exposure (Erikson, 1994, 1995; Gill and Ritchie, 2018). Thus, with uncertainty about the degree to which a community has been exposed to toxins, residents and medical practitioners often have to contend with a contested discourse in identifying not only the nature and extent of health impacts, but even who should be considered a victim (Edelstein, 2004; Erikson, 1994, 1995; KrollSmith and Couch, 1991). Indeed, Gill et al. (2014) show that disruptions following the 1989 Exxon Valdez oil spill continue to affect the well-being of community residents more than two decades after the initial event (see also Gill et al., 2016).

Failure on the part of institutions to prevent a technological disaster represents an explicit challenge to a social system as a whole. Freudenburg theorized recreancy as a concept to "provide an affectively neutral reference to behaviors of persons and/or of institutions that hold positions of trust, agency, responsibility, or fiduciary or other forms of broadly expected obligations to the collectivity, but that behave in a manner that fails to fulfill the obligations or merit the trust" $(1993,916-$ 917), and "the failure of experts or specialized organizations to execute properly responsibilities to the broader collectivity with which they have been implicitly or explicitly entrusted" $(2000,116)$. Thus, considerations of recreancy afford important insights into how a "primary responsible party" is identified and, often, becomes the focal point for blame, hostility, frustration, and, ultimately, compensation (Gill, 2007; Gill et al., 2014; Marshall et al., 2003; Ritchie et al., 2013).

\footnotetext{
${ }^{2}$ Our data does not include measures of participation in litigation. For a review of the consequences of protracted litigation to disaster related community impacts see Gill at al. (2014); Marshall et al. (2003); Marshall et al. (2004); Picou et al. (2004); and Ritchie et al. (2018).
}

Freudenburg's principal concern is the relation between broader social consequences and recreancy. In the wake of a technological disaster, research has shown that perceptions of recreancy amplify the awareness of risk, cultivate emotional/psychological feedback (e.g., anger, distrust, fear, frustration, uncertainty), and even exaggerate perceptions of community damage (e.g., Cope et al., 2016; Freudenburg, 1993; Gill et al., 2014; Gill, 2007; Ritchie, 2012; Ritchie et al., 2013; Ritchie et al., 2018; Scott et al., 2005). As confidence in the social order is shaken, perceptions of recreancy engender new vulnerabilities as community sentiments shift, social bonds are ruptured, and social differentiation is promoted by diverging narratives of distrust and blame (e.g., Alario and Freudenburg, 2003; Clarke and Short, 1993; Cope et al., 2016; Gill et al., 2012; Gill and Ritchie, 2018; Tierney, 2012).

While the EVOS literature has been held up as a "template for understanding oil spill impacts" (Lee and Blanchard, 2012, 27; for an indepth review of the EVOS literature see Gill et al., 2016), another such disaster occurred on the night of 20 April 2010, when an explosion sent gas, oil, and concrete up the wellbore of the BP-leased Deepwater Horizon oil rig located approximately 50 miles offshore of Southeast Louisiana, USA. In addition to the deaths of 11 platform workers, the explosion and subsequent sinking of the rig led to a well breach that gushed millions of gallons of oil into the Gulf of Mexico for nearly three months before it was capped. The DHOS now stands as the largest recorded marine oil spill (Hamilton et al., 2012; Robertson and Krauss, 2010) and "the worst environmental disaster" ever experienced in the United States (Jackson, 2010). While the impacts of the DHOS disaster continue to unfold, it should be noted that EVOS scholars have predicted "[t]he BP disaster as an Exxon Valdez rerun" (Ritchie et al., 2011: 30).

\section{Research questions}

In view of the literature discussed above, we ask the following research questions as they pertain to the residents of the Louisiana communities affected by the DHOS: (1) Does community sentiment change over time? 2) Do the indicators-length of residence, local social bonds, lifecycle stage, and social position-suggested by the systemic community model (Kasarda and Janowitz 1974) predict greater community sentiment? and 3) Do the indicators-mental and physical well-being of community residents and perceptions of recreancy-suggested by the corrosive community model (Freudenburg, 1993, 1997; Picou et al., 2004) predict lower community sentiment in the wake of the disaster?

\section{Methods}

\subsection{Sample}

We address these questions using data from the Louisiana Community Oil Spill Survey (COSS). The COSS is a multi-wave crosssectional dataset that assesses the impacts of the DHOS disaster on Louisiana's coastal residents living in areas most directly affected by the disaster. Administered by Louisiana State University's Public Policy Research Laboratory, the COSS is a telephone survey of households drawn randomly from a listed sample of approximately 6000 households in the coastal zip codes of Plaquemines, Lafourche, and Terrebonne Parishes, and the town of Grand Isle. The areas sampled for the COSS were initially selected because of their direct geographic proximity to the DHOS, were all highly oiled during the disaster, have a high level of involvement in the oil and gas and fishing industries-sectors directly affected by the spill and subsequent drilling and fishing moratoriums-and experienced active cleanup operations for years since the onset of the disaster. The repeated cross-sectional structure of these data affords the unique opportunity to examine the DHOS disaster as a social process, rather than as a single time-point 
event. Four waves of COSS data are used in the analysis: a baseline gathered in October 2010 (the well was declared effectively dead in mid-September), with three follow-up waves collected in April 2011, April 2012, and April 2013 (corresponding to the one-year, two-year, and three-year anniversaries of the onset of the disaster). The respective response rates for each wave were 24, 25, 20, and 19 percent. Despite being obtained during adverse conditions (i.e., a disaster context), it should be noted that such rates of response are well above those typically obtained on contemporary telephone surveys by leading research organizations (e.g., Pew Research Center), and are within a range that is typically not a threat to the quality of survey estimates (Curtin et al., 2000; Groves, 2006; Keeter et al., 2000, 2006).

\subsection{Measures}

\subsubsection{Dependent variable}

Community sentiment, the dependent variable in our analysis, is measured with a six-item index. Items included in the measure were drawn from the Knight Soul of the Community project, a research partnership between Gallup and the Knight Foundation (2012) and have been used in previous investigations of the social impacts of the DHOS (e.g., Cope et al., 2013; Lee and Blanchard, 2012; Parks et al., 2018). Significantly, these measures are analogous to those used in previous research of the social correlates of social disruption/change and community attitudes (e.g., Brown, 1993; Kasarda and Janowitz, 1974; Smith et al., 2001). The index is comprised of the following items:

1. Taking everything into account, how satisfied are you with [name of community residence] as a place to live? $(0=$ very dissatisfied; 1 = fairly dissatisfied; 2 = neither dissatisfied nor satisfied; $3=$ fairly satisfied, or $4=$ very satisfied)

2. How likely are you to recommend [name of community residence] as a place to live? $(0=$ extremely unlikely; 1 = somewhat unlikely; $2=$ neither likely nor unlikely; $3=$ somewhat likely, or $4=$ extremely likely)

3. Thinking about five years from now, how do you think [name of community residence] will be as a place to live compared to today? ( $0=$ Will be much worse; $1=$ Will be somewhat worse; $2=$ Will be about the same; $3=$ Will be somewhat better, or $4=$ Will be much better)

4. Please indicate your agreement with the following statement: I am proud to say that I live in [name of community residence]. $(0=$ strongly disagree; $1=$ disagree; $2=$ neither disagree nor agree; 3 = agree, or $4=$ strongly agree)

5. Please indicate your agreement with the following statement: [Name of community residence] is the perfect place for people like me. ( $0=$ strongly disagree; $1=$ disagree; $2=$ neither disagree nor agree; 3 = agree, or $4=$ strongly agree)

6. Overall, how would you rate your community as a place to live? $(0=$ poor $; 1=$ fair $3=$ good $; 4=$ excellent $)$

Drawing on these six items, we generated a summative index that ranged from 0 to 24 (Cronbach's alpha $=0.79$ ). As shown in Table 1 , there is evidence of a modest increase in community sentiment over the periods studied here.

\subsubsection{Independent variables}

6.2.2.1. Time. To measure change over time, following the approach used in previous research (e.g., Brown et al., 2005; Cope et al., 2016; Parks et al., 2018), indicator variables are created for the second (April 2011), third (April 2012), and fourth (April 2013) waves of the COSS and measured in reference to the first wave (October 2010). In other words, these dichotomous measures (yes $=1$ ) compare the levels of community sentiment in April 2011, April 2012, and April 2013 to levels of community sentiment in October 2010.
Table 1

Descriptive statistics by survey wave.

\begin{tabular}{|c|c|c|c|c|}
\hline \multirow[t]{2}{*}{ Variables } & \multicolumn{2}{|l|}{$\begin{array}{l}\text { October } \\
2010\end{array}$} & April 2012 & April 2013 \\
\hline & $\begin{array}{l}\text { Mean/ } \\
\text { percentage }\end{array}$ & $\begin{array}{l}\text { Mean/ } \\
\text { percentage }\end{array}$ & $\begin{array}{l}\text { Mean/ } \\
\text { percentage }\end{array}$ & $\begin{array}{l}\text { Mean/ } \\
\text { percentage }\end{array}$ \\
\hline \multicolumn{5}{|l|}{ Dependent Variable } \\
\hline $\begin{array}{r}\text { Community } \\
\text { sentiment }\end{array}$ & $15.36(3.33)$ & $15.39(3.62)$ & $15.86(3.06)$ & $15.86(3.10)$ \\
\hline \multicolumn{5}{|l|}{ Systemic community } \\
\hline \multicolumn{5}{|l|}{ Length of residence } \\
\hline $\begin{array}{l}\text { Proportion of a } \\
\text { life as resident }\end{array}$ & $00.83(0.31)$ & $0.85(0.27)$ & $0.87(0.27)$ & $0.80(0.32)$ \\
\hline \multicolumn{5}{|l|}{ Local social bonds } \\
\hline Cajun & $33.30 \%$ & $49.44 \%$ & $58.01 \%$ & $51.80 \%$ \\
\hline $\begin{array}{l}\text { Fishing } \\
\text { employment }\end{array}$ & $19.48 \%$ & $20.51 \%$ & $19.69 \%$ & $17.84 \%$ \\
\hline Oil employment & $27.01 \%$ & $27.41 \%$ & $29.74 \%$ & $29.98 \%$ \\
\hline $\begin{array}{l}\text { Oil \& fishing } \\
\text { employment }\end{array}$ & $33.41 \%$ & $35.43 \%$ & $30.63 \%$ & $26.29 \%$ \\
\hline Catholic & $69.39 \%$ & $71.24 \%$ & $73.43 \%$ & $69.93 \%$ \\
\hline $\begin{array}{l}\text { Church } \\
\text { attendance }\end{array}$ & $3.34(1.50)$ & $3.45(1.47)$ & $3.44(1.48)$ & $3.49(1.58)$ \\
\hline \multicolumn{5}{|l|}{ Lifecycle stage } \\
\hline Age & $\begin{array}{l}44.69 \\
(16.56)\end{array}$ & $\begin{array}{l}48.62 \\
(16.62)\end{array}$ & $\begin{array}{l}49.53 \\
(17.45)\end{array}$ & $\begin{array}{l}52.54 \\
(16.53)\end{array}$ \\
\hline $\begin{array}{c}\text { Number of } \\
\text { children }\end{array}$ & $1.03(1.20)$ & $0.93(1.18)$ & $0.76(1.10)$ & $0.73(1.16)$ \\
\hline $\begin{array}{r}\text { Married or } \\
\text { widowed }\end{array}$ & $73.12 \%$ & $75.16 \%$ & $71.15 \%$ & $79.12 \%$ \\
\hline \multicolumn{5}{|l|}{ Social position } \\
\hline $\begin{array}{l}\text { Educational } \\
\text { attainment } \\
(0-18)\end{array}$ & $12.46(2.41)$ & $12.48(2.36)$ & $12.37(2.46)$ & $12.52(2.46)$ \\
\hline Employed & $61.71 \%$ & $54.76 \%$ & $57.29 \%$ & $53.71 \%$ \\
\hline \multicolumn{5}{|l|}{ Corrosive community } \\
\hline Mental health & $8.17(6.39)$ & $8.44(6.67)$ & $7.14(6.34)$ & $5.94(6.09)$ \\
\hline Physical health & $4.25(5.31)$ & $4.72(5.40)$ & $4.16(5.20)$ & $3.31(4.61)$ \\
\hline Distrust & $63.77 \%$ & $68.38 \%$ & $63.99 \%$ & $60.08 \%$ \\
\hline Blame & $45.49 \%$ & $55.59 \%$ & $45.37 \%$ & $50.02 \%$ \\
\hline \multicolumn{5}{|l|}{ Controls } \\
\hline White & $50.22 \%$ & $35.17 \%$ & $29.19 \%$ & $35.30 \%$ \\
\hline Female & $46.23 \%$ & $43.02 \%$ & $35.97 \%$ & $39.79 \%$ \\
\hline Proximity to coast & $5.37(1.90)$ & 5.33 (1.99) & $5.12(2.05)$ & $5.32(1.97)$ \\
\hline$N$ & 873 & 800 & 575 & 489 \\
\hline
\end{tabular}

Standard deviations in parentheses.

6.2.2.2. Systemic community. To assess the utility of the systemic community model (Kasarda and Janowitz 1974) in predicting community sentiment following the DHOS, our models include measures for the length of residence, local social bonds, lifecycle stage, and social position. Unfortunately, we are not able to directly replicate the exact questions used by Kasarda and Janowitz (1974). Nevertheless, the measures described below speak to the theoretical arguments they presented and are consistent with how many other researchers have used their approach to modeling community (e.g., Brown, 1993; Cope et al., 2015; Flaherty and Brown, 2010).

Length of residence. Length of residence is measured as the proportion of a person's life they have lived in the community (i.e., the quotient of the number of years the respondent was a community resident divided by their age), resulting in a variable that ranges from 0 to 1 . This calculation diverges from measuring the length of residence as the number of years a respondent reported they were a community resident. We take this approach because including the raw number of years residing in the community potentially conflates the effects of age and length of residence (Cope et al., 2015; Flaherty and Brown, 2010; Goodsell et al., 2008).

Local social bonds. Local social bonds are measured in three ways. First, to measure social bonds that derive from membership in a large local ethnic group, we distinguished Cajuns from all other groups 
(Cajun = 1) (Henry and Bankston, 2002; Roebuck and Hickson, 1982). Second, to measure local social bonds attributable to connection to the community economic identity, what Kasarda and Janowitz (1974: 329) refer to as ties to local "occupational systems," we include a set of variables that measure respondents' association with two critical industries in the region: the oil/gas industry and the fishing/seafood industry (Bernard, 2003; Henry and Bankston, 2002; Paul et al., 2012; Roebuck and Hickson, 1982). Specifically, indicator variables were created based on responses to the following questions: "Do you or any member of your immediate family currently work in the oil industry?" (yes $=1$ ) and "Do you or any member of your immediate family currently work in the fishing or seafood industries?" (yes $=1$ ). Since these are not necessarily mutually exclusive categories (see e.g., Freudenburg and Gramling, 2011) - it is possible that a household could have members employed in both the oil and fishing industries-we also include a third indicator variable for households with fishers and oil workers (yes $=1$ ). These three indicators are mutually exclusive. Finally, we measure religious identification using two variables: an indicator variable for membership in the predominant religious group in the region (Catholic $=1$ ) and a 5-point ordinal scale on which higher numbers indicate more frequent church attendance (Henry and Bankston, 2002; Paul et al., 2012).

Lifecycle stage. Three variables are used to measure the effect of respondents' lifecycle stage: 1 ) age, measured as a continuous variable in years; 2) the number of children age 17 years or younger living in the respondent's household, truncated at 7 or more; and 3) marital status, coded 1 for respondents who were married or widowed (see Brown, 1993; Cope et al., 2015; Flaherty and Brown, 2010). ${ }^{3}$

Social position. We include two variables to account for the effect of respondents' social position. The first is the number of years of schooling respondents completed (which ranges from 0 to 18). We also measure respondents' social position by including an indicator variable for being employed (yes = 1).

6.2.2.3. Corrosive community. To assess the utility of the corrosive community model (Freudenburg, 1993, 1997; 2000; Freudenburg and Jones, 1991; Picou et al., 2004) in predicting community sentiment following the DHOS, our models include measures for mental health, physical health, and recreancy.

Mental health. Mental health impacts are measured with an index of negative affective states attributed to the spill. Respondents were asked: "In the last week, how often have you experienced the following feelings because of the oil spill?" (Responses included almost constantly, some of the time, almost never, and never). The list of feelings included worry, sadness, nervousness, fear, depression, anxiety, and anger. Each item ranged from 0 to 3 , where $0=$ never and $3=$ almost constantly. We created an index by summing the scores across all seven indicators, which resulted in a measure that ranged from 0 to 21 (Cronbach's alpha $=0.92$ ).

Physical health. Physical health impacts are measured with an index of physical ailments attributed to the spill. Respondents were asked: "In the last week, how often have you experienced the following physical symptoms because of your worries about the oil spill?" (Again, responses included almost constantly, some of the time, almost never, and never). The list of physical symptoms included sick stomach, diarrhea, headaches, joint pain, loss of appetite, chest pain, and shortness of breath. Again, each item ranged from 0 to 3 , where $0=$ never and 3 = almost constantly. We created an index by summing the scores across all seven indicators, which resulted in a measure that ranged from 0 to 21 (Cronbach's alpha $=0.88$ ).

Recreancy. We measure recreancy using two variables. With respect

\footnotetext{
${ }^{3}$ We combine married and widowed here for the sake of consistency with previous research. Ancillary analysis using only married (yes $=1$ ) produced similar substantive results.
}

to distrust, three binary measures were obtained by asking respondents to indicate whether they "trust information regarding the oil spill" from $\mathrm{BP}$, the federal government, and the state government (no $=1)$. Based on this information, a dichotomous variable was created that measures whether the respondent distrusted 2 or more of the institutional actors above (yes = 1). Similarly, we use three binary measures that reference blame by asking respondents who they "blame for the consequences of the oil spill, such as oil in the marsh, the moratorium on drilling and the closure of fisheries." The responses were BP, the federal government, and the state government (yes $=1$ ). Based on this information, a dichotomous variable was created that measures whether the respondent blamed two or more of the institutional actors above for negative consequences of the spill (yes $=1$ ). Our decision to use dichotomous measures of distrust and blame is grounded in the research literature that suggests, throughout the disaster process, other institutional actors-beyond the primary responsible party-are often drawn into the web of culpability (e.g., Cope et al., 2016). The dichotomized measures highlight whether recreancy is extending beyond the primary responsible party.

\subsubsection{Controls}

We include three control variables in our models in addition to those outlined above. ${ }^{4}$ Specifically, we control for respondents' race (White $=1$ ), sex (female $=1$ ), and an 8-point ordinal scale measuring proximity to the coast (larger values denote greater distance). In our discussion of the results we focus on relationships between community sentiment and our independent variables. Descriptive statistics for all variables used in the analysis are shown in Table 1.

\subsection{Modeling strategy}

We use ordinary least squares (OLS) regression models to predict levels of community sentiment in the wake of the DHOS. Specifically, we regress community sentiment on change over time (Model 1), systemic community (Model 2), corrosive community (Model 3), and a full model including all predictors (Model 4). To address differential probabilities in sample selection related to higher levels of nonresponse amongst certain segments of the population, we weight our models by age and sex on the basis of the ratio of the distributions of these groups in the COSS versus those drawn from corresponding zip codes from the 2005-2009 five-year estimates of the American Community Survey. ${ }^{5}$

\section{Results}

Table 2 presents OLS regression models predicting community sentiment. Model 1 includes only the indicators of time and controls.

\footnotetext{
${ }^{4}$ To "compare the relative merits" of different models of community (1974: 330), Kasarda and Janowitz included measures of population size and density in their models. In the models presented in this paper, we have elected not to include these controls. Our logic in forgoing the inclusion of indicators for population size and density is twofold: 1) they were not theorized as part of the systemic model of community, and 2) ancillary analysis did not show significant relationships between these variables and community sentiment.

${ }^{5}$ We use the 2005-2009 5-year ACS estimates rather than the 2010 Census data to calculate the weights for the COSS for two reasons. The first is differences in the time frame reference for ACS versus the Census. According to the US Census U.S. Census Bureau (2018), a key difference between the ACS and the decennial census is the overall time frame in which they are conducted. The data from the decennial census describes the characteristics of the population in the March through June of the census year, while ACS data describe the characteristics nearly every day over the full calendar year. A second, and more practical reason, is that the 2010 Census data was not made publicly available until 2012. Continuing to use the 2005-2009 ACS estimates to weight the data makes the current analysis consistent with published work using the COSS that preceded that data release (Cope et al., 2013; Lee and Blanchard, 2012).
} 
Table 2

OLS regression model predicting community sentiment.

\begin{tabular}{|c|c|c|c|c|c|c|c|c|}
\hline & \multicolumn{2}{|l|}{ Model 1} & \multicolumn{2}{|l|}{ Model 2} & \multicolumn{2}{|l|}{ Model 3} & \multicolumn{2}{|l|}{ Model 4} \\
\hline & $\mathrm{b}$ & SE & $\mathrm{b}$ & SE & $\mathrm{b}$ & SE & $\mathrm{b}$ & SE \\
\hline \multicolumn{9}{|l|}{ Time } \\
\hline \multicolumn{9}{|l|}{ October 2010 (reference) } \\
\hline April 2011 & 0.049 & 0.116 & & & & & 0.052 & 0.112 \\
\hline April 2012 & $0.536 * * *$ & 0.127 & & & & & $0.356^{* * \dagger}$ & 0.124 \\
\hline April 2013 & $0.514^{* * *}$ & 0.138 & & & & & $0.310 * \dagger$ & 0.135 \\
\hline \multicolumn{9}{|l|}{ Systemic community } \\
\hline \multicolumn{9}{|l|}{ Length of residence } \\
\hline Proportion of a life as resident & & & $0.622^{* * *}$ & 0.160 & & & $0.740^{* * *}$ & 0.157 \\
\hline \multicolumn{9}{|l|}{ Local social bonds } \\
\hline Cajun & & & -0.067 & 0.143 & & & -0.039 & 0.141 \\
\hline Fishing employment & & & $0.529 * * *$ & 0.145 & & & $0.904 * * *+$ & 0.145 \\
\hline Oil employment & & & $0.269^{*}$ & 0.133 & & & $0.316^{*}$ & 0.130 \\
\hline Oil \& fishing employment & & & $0.272^{*}$ & 0.132 & & & $0.593^{* * *+}$ & 0.131 \\
\hline Catholic & & & $0.866^{* * *}$ & 0.104 & & & $0.820 * * *$ & 0.102 \\
\hline Church attendance & & & $0.133^{* * *}$ & 0.031 & & & $0.115^{* * *}$ & 0.030 \\
\hline \multicolumn{9}{|l|}{ Lifecycle stage } \\
\hline Age & & & $0.012^{* * *}$ & 0.003 & & & $0.012^{* * *}$ & 0.003 \\
\hline Number of children & & & $-0.149^{* * *}$ & 0.044 & & & $-0.125^{* *}$ & 0.043 \\
\hline Married or widowed & & & $0.306^{* *}$ & 0.114 & & & $0.308^{* *}$ & 0.112 \\
\hline \multicolumn{9}{|l|}{ Social position } \\
\hline Educational attainment & & & $-0.061^{* *}$ & 0.020 & & & $-0.078^{* * *}$ & 0.019 \\
\hline Employed & & & $0.667^{* * *}$ & 0.100 & & & $0.593^{* * *}$ & 0.099 \\
\hline \multicolumn{9}{|l|}{ Corrosive community } \\
\hline Mental health & & & & & $-0.054^{* * *}$ & 0.010 & $-0.061^{* * *}$ & 0.010 \\
\hline Physical health & & & & & $-0.034^{* *}$ & 0.012 & $-0.028^{*}$ & 0.012 \\
\hline Distrust & & & & & $-0.564^{* * *}$ & 0.098 & $-0.595^{* * * \S}$ & 0.096 \\
\hline Blame & & & & & -0.106 & 0.091 & $-0.221 *$ & 0.090 \\
\hline \multicolumn{9}{|l|}{ Controls } \\
\hline White & 0.125 & 0.095 & 0.125 & 0.142 & -0.004 & 0.093 & $0.133+8+$ & 0.140 \\
\hline Female & $-0.189 *$ & 0.093 & -0.111 & 0.094 & -0.170 & 0.092 & $-0.019 \dagger$ & 0.093 \\
\hline Proximity to coast & $0.127 * * *$ & 0.023 & $0.100 * * *$ & 0.023 & $0.075^{* * *}$ & 0.023 & $0.070 * \approx \varangle+$ & 0.023 \\
\hline Intercept & $14.703^{* * *}$ & 0.160 & $12.889^{* * *}$ & 0.374 & $16.200^{* * *}$ & 0.169 & $13.982^{* * * \dagger}$ & 0.382 \\
\hline Adj. $R^{2}$ & 0.011 & & 0.056 & & 0.039 & & 0.095 & \\
\hline
\end{tabular}

$N=2739 . * \mathrm{p}<0.05 ; * * \mathrm{p}<0.01 ; * * \mathrm{p}<0.001$.

$\uparrow$ corresponding coefficients in the Model 1 and Model 4 are significantly different $(\mathrm{p}<0.05)$.

₹ corresponding coefficients in the Model 2 and Model 4 are significantly different ( $<<0.05$ ).

$\S$ corresponding coefficients in the Model 3 and Model 4 are significantly different $(\mathrm{p}<0.05$ ).

The results show significantly greater levels of community sentiment in April 2012 and April 2013 compared to October 2010. In other words, respondents reported greater community sentiment two and three years out from the spill compared to in its immediate aftermath.

Model 2 includes only the systemic community model variables and controls. Consistent with theoretical expectations, length of residence is a significant determinant of community sentiment, with respondents who have lived more of their lives in their present community reporting greater community sentiment. In terms of local social bonds, the results demonstrate a positive and significant relationship for all measures, with the exception of membership in the region's largest ethnic group-Cajuns-which is not statistically significant. Moreover, all three variables used to measure lifecycle stage are also shown to be significant determinates of community sentiment. Specifically, older and married/widowed respondents report more positive community attitudes, while households with greater numbers of children age 17 or younger are associated with lower levels of community sentiment. Concerning our measures of social position, the results show that higher levels of education are significantly associated with lower levels of community sentiment, while, conversely, being employed is significantly correlated with greater community sentiment.

Model 3 includes only the corrosive community model variables and controls. The results indicate that greater negative mental and physical health impacts attributed to the DHOS are associated with significantly lower community sentiment. Likewise, distrusting information regarding the oil spill from two or more institutional actors (BP, the federal government, and/or the state government) is associated with significantly less community sentiment. In contrast, blaming two or more institutional actors for the negative consequences of the oil spill-such as oil in the marsh, and moratoria on oil drilling and fishing-is not statistically significant.

Last, Model 4 is a full model including measures of time, systemic community, corrosive community, and controls. The results demonstrate the same general pattern of relationships shown in the previous models continue to hold in the presence of the full range of other predictors. The one notable exception is that, consistent with theory, in the full model blaming two or more institutional actors for the negative consequences of the oil spill becomes a significant predictor of lower levels of community sentiment. While the inclusion of other predictors significantly ameliorates these effects, community sentiment remains significantly higher in April 2012 and April 2013 compared to October 2010. Moreover, the positive relationship between ties to the fishing industry and community sentiment is significantly greater in the full model (compared to Model 2), indicating that after accounting for time and corrosive community, fishers possess even higher levels of community sentiment compared to non-fishers. In addition, the negative association between distrust and community sentiment becomes significantly greater as well (compared to Model 3), demonstrating that 
distrust is related to even lower levels of community sentiment net of other factors. ${ }^{6}$

\section{Discussion}

This study addressed three objectives concerning community sentiment in the wake of the DHOS. Specifically, we examined how community sentiment following the DHOS 1) changed over time; 2) was related to the systemic model of community (Kasarda and Janowitz, 1974); and 3) was related to the corrosive model of community (Freudenburg, 1993, 1997; 2000; Freudenburg and Jones, 1991; Picou et al., 2004). The results show that while other factors ameliorate these effects, community sentiment was significantly higher at later time points, namely April 2012 and April 2013 compared to October 2010. With respect to the second objective, our results confirm the utility of the systemic community model in predicting community sentiment in a disaster context. Finally, regarding the third objective, our findings also confirm the applicability of the corrosive community model in predicting community sentiment following the DHOS. Overall, our findings suggest these models complement one another, simultaneously operating in a manner suggested by each theoretical frame.

As we near the ten-year anniversary of the onset of the DHOS disaster, our study provides important contributions to the extant social scientific understanding of disasters (e.g., Drabek, 2013; Erikson, 1976, 1995, 1994; Lindell, 2013; Perry, 2018; Quarantelli, 2005; Quarantelli and Dynes, 1977; Tierney, 2014), including the literature on oil spillrelated disaster processes (e.g., Cope et al., 2013, 2016; Gill et al., 2014; Lee and Blanchard., 2012; Ritchie et al., 2013). Specifically, we attended to measures associated with the systemic model of community (e.g., Beggs et al., 1996; Brown, 1993; Cope et al., 2015; Flaherty and Brown, 2010; Gerson et al., 1977; Krannich and Greider, 1990) and the corrosive community model in a technological disaster context (e.g., Gill, 2007; Gill et al., 2016; Marshall et al., 2003; Picou et al., 2004; Ritchie et al., 2013). We show that these theories do well to simultaneously predict community sentiment, which in the wake of the DHOS had previously been identified as key aspects of disaster resilience and recovery (e.g., Cope et al., 2013; Lee and Blanchard, 2012; Parks et al., 2018). In doing so, we contribute to a broader sociological understanding of disasters, sense of community, social systems, and "chronic corrosive processes" (Picou et al., 2007: 25).

Despite these contributions, our study has several limitations. For example, a key component of the corrosive community thesis is involvement in protracted litigation (Picou et al., 2004; Gill and Picou, 1998; Marshall et al., 2003). While litigation related to the DHOS was taking place during the period under study here, we do not have direct measures of respondents' participation in the legal claims process. Ritchie et al. (2018), in particular, provide an important treatment of this issue following the DHOS. Additionally, our models did not include measures of social ties that captured the range of stronger-to-weaker ties (Granovetter, 1973) or other indicators of social capital, both of which have been shown to be important indicators for understanding differential social impacts following a disaster (Adeola and Steven Picou, 2014; Aldrich and Meyer, 2015; Ritchie, 2012; Ritchie and Gill, 2010). It is also important to recognize that our models do not allow us to establish causation (i.e., the old adage that "correlation is not causation" applies here). For example, is it that greater mental health problems reduce community sentiment, or that lower levels of community sentiment increase mental health problems? We cannot say, we can only say that they are related. Last, it is important to note that this study is based on cross-sectional trend data and thus cannot assess within-unit change in the variables over time. Future studies should

\footnotetext{
${ }^{6}$ Cross model comparisons are based on the methods for comparing regression coefficients advocated by Clogg et al. (1995), and were conducted using Stata's Seemingly Unrelated Estimation (suest) command (v15.1).
}

consider a longitudinal cohort panel design to better account for these types of dynamics. Doing so, would allow for more formal tests of how community sentiments shift and emerge in relation to changing conditions. Similarly, qualitative investigations would provide greater nuance depth, and an opportunity to ground-truth quantitative findings.

In conclusion, we highlight the words of Dowty and Allen (2011: 203), who state: "Whether a disaster is deemed 'natural' or 'man-made,' all disasters begin and end in communities and the social groups, networks, and politics that sustain them" (emphasis added). As such, this research holds a number of applied implications. First, it highlights that the characteristics and attributes of people and places influence disaster impacts. Given that risks, costs, and impacts-indeed the very consideration of what constitutes a disaster-are socially constructed, the results of this study are consistent with the greater body of social science research which maintains that communities and their residents should be central in disaster mitigation planning. Disaster preparedness and response planners should be attuned to the likelihood that different types of disasters will have differential consequences for certain types of people in affected locales. Accordingly, as a central aspect of disaster mitigation/preparedness strategies, community development efforts need to be attuned to social attributes that may serve to mute or amplify disaster-related impacts, such as community sentiment. Finally, this research adds to the chorus of researchers who have long contended that planners need to recognize that disasters are not singular events but processes linked to social antecedents and long-term consequences.

\section{Funding}

This research was made possible by a grant from The Gulf of Mexico Research Initiative, with additional support provided by a Brigham Young University Mentoring Environment Grant. Data are publicly available through the Gulf of Mexico Research Initiative Information \& Data Cooperative (GRIIDC) at https://data.gulfresearchinitiative.org (doi:10.7266/N7T72FDS， 10.7266/N7PG1PP2， 10.7266/N7JQ0XZB, 10.7266/N7DZ068V).

\section{CRediT authorship contribution statement}

Michael R. Cope: Conceptualization, Methodology, Formal analysis, Investigation, Resources, Data curation, Writing - original draft, Writing - review \& editing, Visualization, Supervision, Funding acquisition. Tim Slack: Methodology, Investigation, Resources, Data curation, Writing - review \& editing, Visualization, Supervision, Funding acquisition. Jorden E. Jackson: Data curation, Writing - review \& editing. Vanessa Parks: Data curation, Writing - review \& editing.

\section{Appendix A. Supplementary data}

Supplementary data to this article can be found online at https:// doi.org/10.1016/j.jrurstud.2019.12.019.

\section{References}

Adeola, Francis O., Steven Picou, J., 2014. Social capital and the mental health impacts of Hurricane Katrina: assessing long-term patterns of psychosocial distress. Int. J. Mass Emergencies Disasters 32 (1), 121-156.

Alario, Margarita, Freudenburg, William, 2003. The Paradoxes of modernity: scientific advances, environmental problems, and risks to the social fabric? Sociol. Forum 18 (2), 193-214.

Aldrich, Daniel P., Kyota, Emi, 2017. Creating community resilience through elder-led physical and social infrastructure. Disaster Med. Public Health Prep. 11 (1), 120-126.

Aldrich, Daniel P., Meyer, Michelle A., 2015. Social capital and community resilience. Am. Behav. Sci. 59 (2), 254-269.

Bauman, Zygmunt, 2001. Community: Seeking Safety in an Insecure World. Polity Press, Malden, MA.

Beggs, John J., Hurlbert, Jeanne S., Haines, Valerie A., 1996. Community attachment in a rural setting: a refinement and empirical test of the systemic model. Rural Sociol. 61 (3), 407-426. 
Bernard, Shane K., 2003. The Cajuns: Americanization of a People. University Press of Mississippi, Jackson, MS.

Brown, R.B., Dorius, S.F., Krannich, R.S., 2005. The boom-bust-recovery cycle: Dynamics of change in community satisfaction and social integration in Delta, Utah. Rural Sociol. 70 (1), 28-49.

Bucher, Rue, 1957. Blame and hostility in disaster. Am. J. Sociol. 62 (5), 467-475.

Bolin, Bob, Kurtz, Liza C., 2018. Race, class, ethnicity, and disaster vulnerability. In: Handbook of Disaster Research. Springer, Cham, pp. 181-203.

Bonanno, George, A., Brewin, Chris R., Kaniasty, Krzysztof, Annette, M., La Greca, 2010. Weighing the costs of disaster consequences, risks, and resilience in individuals, families, and communities. Psychol. Sci. Public Interest 11 (1), 1-49.

Brown, Ralph B., 1993. Rural community satisfaction and attachment in mass consumer society. Rural Sociol. 58 (3), 387-403.

Chhotray, Vasudha, Few, Roger, 2012. Post-disaster recovery and ongoing vulnerability: ten years after the super-cyclone of 1999 in Orissa, India. Glob. Environ. Chang. 22 (3), 659-702.

Clarke, Lee, Short Jr., James F., 1993. Social organization and risk: some current controversies. Annu. Rev. Sociol. 19 (1), 375-399.

Clogg, Clifford C., Petkova, Eva, Cheng, Tzuwei, 1995. Reply to Allison: more on comparing regression coefficients. Am. J. Sociol. 100 (5), 1305-1312.

Cope, Michael R., Flaherty, Jeremy, Young, Kirk D., Brown, Ralph B., 2015. "Olympic boomtown: the social impacts of a one-time mega-event in Utah's Heber valley. Sociol. Spectr. 35 (2), 136-160.

Cope, Michael R., Lee, Matthew R., Slack, Tim, Blanchard, Troy C., Carney, Jeff, Lipschitz, Forbes, Gikas, Lydia, 2018. Geographically distant social networks elevate perceived preparedness for coastal environmental threats. Popul. Environ. 39 (3), 277-296.

Cope, Michael R., Slack, Tim, Blanchard, Troy C., Lee, Matthew R., 2016. It's not whether you win or lose, it's how you place the blame: assessing perceptions of blame for the deepwater horizon oil spill. Rural Sociol. 81 (3), 295-315.

Cope, Michael R., Slack, Tim, Blanchard, Troy C., Lee, Matthew R., 2013. Does time heal all wounds? Community attachment, natural resource employment, and health impacts in the wake of the BP deepwater horizon disaster. Soc. Sci. Res. 42 (3), 872-881.

Curtin, Richard, Presser, Stanley, Singer, Eleanor, 2000. The effects of response rate changes on the index of consumer sentiment. Public Opin. Q. 64 (4), 413-428.

Davidson, William, Cotter, Patrick R., 1991. The relationship between sense of community and subjective well-being: a first look. J. Community Psychol. 19 (3), 246-253.

de Tocqueville, Alexis, 2000. Democracy in America Trans. Henry Reeve, New York, NY: Bantam Dell [1840].

Dowty, Rachel A., Allen, Barbara L., 2011. Afterword. In: Dowty, Rachel A., Allen, Barbara L. (Eds.), Dynamics of Disaster: Lessons on Risk, Response and Recovery. Earthscan, Washington, DC, pp. 203-207.

Drabek, Thomas E., 1986. Human System Responses to Disaster: an Inventory of Sociological Findings. Springer-Verlag, New York, NY.

Drabek, T.E., 2013. The Human Side of Disaster, 2nd. CRC Press, New York, NY.

Dynes, Russell R., 1974. Organized Behavior in Disaster. Disaster Research Center, University of Delaware.

Edelstein, Michael R., 2004. Contaminated Communities: Coping with Residential Toxic Exposure. Westview Press, Boulder, CO.

Elias, N., Scotson, J.L., 1965. The Established and the Outsiders: A Sociological Enquiry into Community Problems. Frank Cass \& Co. LTD, London, UK.

Erikson, Kai, 1995. Notes on trauma and community. In: Trauma: Exploration in Memory Edited by Cathy Caruth Baltimore, MD, pp. 183-199.

Erikson, Kai, 1994. A New Species of Trouble: the Human Experience of Modern Disasters. W.W. Norton \& Company, New York, NY.

Erikson, Kai, 1976. Everything in its Path: Destruction of Community in the Buffalo Creek Flood. Simon and Schuster, New York, NY.

Flaherty, Jeremy, Brown, Ralph B., 2010. A multilevel systemic model of community attachment: assessing the relative importance of the community and individual levels. Am. J. Sociol. 116 (2), 503-542.

Freudenburg, William R., 2000. The 'risk society' reconsidered: recreancy, the division of labor, and risk to the social fabric. In: Cohen, Maurie J. (Ed.), Risk in the Modern Age: Social Theory, Science and Environmental Decision-Making. St. Martin's Press, New York, NY, pp. 107-122.

Freudenburg, William R., 1997. Contamination, corrosion, and the social order: an overview. Curr. Sociol. 45 (3), 19-40.

Freudenburg, William R., 1993. Risk and recreancy: Weber, the division of labor, and the rationality of risk perceptions. Soc. Forces 71 (4), 909-932.

Freudenburg, William R., Gramling, Robert, 2011. Blowout in the Gulf: the BP Oil Spill Disaster and the Future of Energy in America. The MIT Press, Cambridge, MA.

Freudenburg, William R., Jones, Timothy R., 1991. Attitudes and stress in the presence of technological risk: a test of the Supreme Court hypothesis. Soc. Forces 69 (4), 1143-1168.

Fritz, Charles E., 1961. Disasters. In: Merton, Robert K., Nisbet, Robert A. (Eds.), Contemporary Social Problems: an Introduction to the Sociology of Deviant Behavior and Social Disorganization. Harcourt Brace and World, New York, NY, pp. 651-694.

Fritz, Charles E., Marks, Eli S., 1954. The NORC studies of human behavior in disaster. J. Soc. Issues 10 (3), 26-41.

Gerson, Kathleen, Ann Stueve, C., Fischer, Claude S., 1977. Attachment to place. 139-61 In: Fischer, C.S., Jackson, R.M., Stueve, C.A., Gerson, K., Jones, L.M., Baldassare, M. (Eds.), Networks and Places: Social Relations in the Urban Setting. Free Press, New York, NY.

Gill, Duane A., 2007. Secondary trauma or secondary disaster? Insights from Hurricane Katrina. Sociol. Spectr. 27 (6), 613-632.

Gill, Duane A., Steven Picou, J., 1998. Technological disaster and chronic community stress. Soc. Nat. Resour. 11 (8), 795-815.
Gill, Duane A., Steven Picou, J., Ritchie, Liesel A., 2012. The exxon valdez and BP oil spills: a comparison of initial social and psychological impacts. Am. Behav. Sci. 56 (1), 3-23.

Gill, Duane A., Ritchie, Liesel A., Steven Picou, J., 2016. Sociocultural and psychosocial impacts of the exxon valdez oil spill: twenty-four years of research in Cordova, Alaska. Extr. Ind. Soc. 3 (4), 1105-1116.

Gill, Duane A., Liesel, A. Ritchie, Picou, J. Steven, Langhinrichsen-Rohling, Jennifer, Michael, A. Long, Shenesey, Jessica W., 2014. The Exxon and BP oil spills: a comparison of psychosocial impacts. Nat. Hazards 74 (3), 1911-1932.

Gill, Duane A., Ritchie, Liesel A., 2018. Contributions of technological and Natural disaster research to the social science disaster paradigm. In: Handbook of Disaster Research. Springer, Cham, pp. 39-60.

Goodsell, Todd L., Flaherty, Jeremy, Brown, Ralph B., 2014. Community as Moral Proximity: Theorizing Community in a Global Economy. In: Bailey, Conner, Jensen, Leif, Ransom, Elizabeth (Eds.), Rural America in a Globalizing World: Problems and Prospects for the 2010s. West Virginia University Press, Morgantown, WV, pp. 626-641.

Goodsell, Todd L., Brown, Ralph B., Stovall, Joshua, Simpson, Mark, 2008. Globally embedded community: satisfaction and attachment in vance, Alabama. Community Dev. 39 (1), 17-34.

Granovetter, Mark S., 1973. The strength of weak ties. Am. J. Sociol. 78, 1360-1380.

Green, Bonnie L., 1996. Traumatic stress and disaster: mental health effects and factors influencing adaptation. In: In: Mak, Felice L., Nadelson, Carol C. (Eds.), International Review of Psychiatry, vol. 2. American Psychiatric Press, Arlington, VA, pp. 177-210.

Groves, Robert M., 2006. Nonresponse rates and nonresponse bias in household surveys. Public Opin. Q. 70 (5), 646-675.

Grzeskowiak, Stephan, M., Joseph, Sirgy, Widgery, Robin, 2003. Residents' satisfaction with community services: predictors and outcomes. J. Reg. Anal. Policy 33 (2), 1-36.

Halpern, James, Tramontin, Mary, 2007. Disaster Mental Health: Theory and Practice. Thomson Brooks/Cole, Belmont, CA.

Hamilton, Lawrence C., Safford, Thomas G., Ulrich, Jessica D., 2012. In the wake of the spill: environmental views along the Gulf coast. Soc. Sci. Q. 93 (4), 1053-1064.

Hawkins, Robert L., Maurer, Katherine, 2011. You fix my community, you have fixed my life': the disruption and rebuilding of ontological security in New Orleans. Disasters 35 (1), 143-159.

Henry, Jacques M., Bankston III., Carl L., 2002. Blue Collar Bayou: Louisiana Cajuns in the New Economy of Ethnicity. Praeger, Westport, CT.

Jackson, Lisa P., 2010. Remarks of U.S. EPA administrator. In: Jackson, Lisa P. (Ed.), Presented at the 2010 Small Business Environmental Conference, June 8. Retrieved from. http://yosemite.epa.gov/opa/admpress.nsf/0/ 2F14E90B19C8A5A48525773C00614CC8.

Kasarda, John D., Janowitz, Morris, 1974. Community attachment in mass society. Am. Sociol. Rev. 39, 328-339.

Keeter, Scott, Miller, Carolyn, Kohut, Andrew, Groves, Robert M., Presser, Stanley, 2000. Consequences of reducing nonresponse in a large national telephone survey. Public Opin. Q. 64 (2), 125-148.

Keeter, Scott, Kennedy, Courtney, Dimock, Michael, Best, Jonathan, Craighill, Peyton, 2006. Gauging the impact of growing nonresponse on estimates from a national RDD telephone survey. Public Opin. Q. 70 (5), 759-779.

Kendra, James M., Wachtendorf, Tricia, 2007. Community innovation and disasters. In: Rodrígues, Havidán, Quarantelli, Enrico L., Dynes, Russell R. (Eds.), Handbook of Disaster Research. Springer, New York, NY, pp. 316-334.

Killian, Lewis M., 1954. Some accomplishments and some needs in disaster study. J. Soc. Issues 10 (3), 66-72.

Kimweli, David S., Stilwell, William E., 2002. Community subjective well-being, personality traits and quality of life therapy. Soc. Indic. Res. 60 (1-3), 193-215.

Kroll-Smith, J. Stephen, Robert Couch, Stephen, 1991. As if exposure to toxins were not enough: the social and cultural system as a secondary stressor. Environ. Health Perspect. 95, 61-66.

Kroll-Smith, S., 2018. Recovering Inequality: Hurricane Katrina, the San Francisco Earthquake of 1906, and the Aftermath of Disaster. University of Texas Press, Austin, TX.

Kroll-Smith, J. Stephen, Couch, Stephen Robert, 1990. The Real Disaster Is above Ground: A Mine Fire and Social Conflict. University Press of Kentucky, Lexington, KY.

Kroll-Smith, J. Stephen, Couch, Stephen Robert, 1993. Technological hazards. In: Wilson, J.P., Raphael, B. (Eds.), International Handbook of Traumatic Stress Syndromes. Springer, Boston, MA, pp. 79-91.

Knight Soul of the Community, 2012. Gallup and the John S. And James L. Knight Foundation. Retrieved from. http://www.soulofthecommunity.org/.

Krannich, Richard S., Greider, Thomas, 1990. Rapid growth effects on rural community relations. In: Luloff, A.E., Swanson, L. (Eds.), American Rural Communities. Westview Press, Boulder, CO, pp. 61-73.

Kreps, Gary A., 1989. Social Structure and Disaster. Associated University Presses, Cranbury, NJ.

Kreps, Gary A., 1998. Disaster as systemic event and social catalyst. In: Quarantelli, Enrico L. (Ed.), What Is a Disaster?: A Dozen Perspectives on the Question. Routledge, New York, NY, pp. 31-55.

Lee, Matthew R., Blanchard, Troy C., 2012. Community attachment and negative affective states in the context of the BP deepwater horizon disaster. Am. Behav. Sci. 56 (1), 24-47.

Lindell, M.K., 2013. Disaster studies. Curr. Sociol. 61 (5-6), 797-825.

Maguen, Shira, Neria, Yuval, Conoscenti, Lauren M., Litz, Brett T., 2009. Depression and prolonged grief in the wake of disasters. In: Neria, Yuval, Galea, Sandro, Norris, Fran H. (Eds.), Mental Health and Disasters. Cambridge University, New York, NY, pp. $116-130$.

Marshall, Brent K., Steven Picou, J., Gill, Duane A., 2003. Terrorism as disaster: selected 
commonalities and long-term recovery for 9/11 survivors. Res. Soc. Probl. Public Policy 11, 73-96.

Marshall, Brent K., Steven Picou, J., Schlichtmann, Jan, 2004. Technological disasters, litigation stress and the use of alternative dispute resolution mechanisms. Law Policy 26 (2), 289-307.

McFarlane, Alexander C., Van Hooff, Miranda, Goodhew, Freya, 2009. Anxiety disorders and PTSD. In: Neria, Yuval, Galea, Sandro, Norris, Fran H. (Eds.), Mental Health and Disasters. Cambridge University, New York, NY, pp. 47-66.

McMillan, David W., Chavis, David M., 1986. Sense of community: a definition and theory. J. Community Psychol. 14 (1), 6-23.

McSpirit, Stephanie, Scott, Shauna, Gill, Duane, Hardesty, Sharon, Sims, Dewayne, 2007. Risk perceptions after a coal waste impoundment failure: a survey assessment. South. Rural Sociol. 22, 83-110.

Miles, Scott B., 2015. Foundations of community disaster resilience: wellbeing, identity, services, and capitals. Environ. Hazards 14 (2), 103-121.

Moore, Harry Estill, 1958. Tornadoes over Texas: A Study of Waco and San Angelo in Disaster. University of Texas Press, Austin, TX.

Neria, Yuval, Nandi, Arijit, Galea, Sandro, 2008. Post-traumatic stress disorder following disasters: a systematic review. Psychol. Med. 38 (4), 467-480.

Norris, Fran H., Stevens, Susan P., Pfefferbaum, Betty, Wyche, Karen F., Pfefferbaum, Rose L., 2008. Community resilience as A metaphor, theory, set of capacities, and strategy for disaster readiness. Am. J. Community Psychol. 41 (1-2), 127-150.

Parks, Vanessa, Drakeford, Leah, Cope, Michael R., Slack, Tim, 2018. Disruption of routine behaviors following the deepwater horizon oil spill. Soc. Nat. Resour. 31 (3), 277-290.

Paul, Crystal, Cowley, Amanda, Schafer, Mark J., Banchard, Troy, 2012. Ethnic Groups in the Gulf of Mexico Region: Cajuns. LSU AgCenter Research Report \#118. Louisiana State University Agricultural Center, Baton Rouge, LA.

Peacock, Walter Gillis, Ragsdale, A. Kathleen, 1997. Social systems, ecological networks and disasters: towards a socio-political ecology of disasters. In: Gillis Peacock, Walter, Hearn Morrow, Betty, Gladwin, Hugh (Eds.), Hurricane Andrew: Ethnicity, Gender and the Sociology of Disasters. Routledge, New York, NY, pp. 20-35.

Perry, Ronald W., 2018. Defining disaster: an evolving concept. In: Handbook of Disaster Research. Springer, Cham, pp. 3-22.

Picou, J. Steven, Brunsma, David L., Overfelt, David, 2007. Katrina as paradigm shift: reflections on disaster research in the twenty-first century. In: Brunsma, David L., Overfelt, David, Steven Picou, J. (Eds.), The Sociology of Katrina: Perspectives on a Modern Catastrophe. Rowman \& Littlefield Publishers, INC, New York, NY, pp. $18-32$.

Picou, J. Steven, Marshall, Brent K., Gill, Duane A., 2004. Disaster, litigation and the corrosive community. Soc. Forces 82 (4), 1448-1482.

Quarantelli, Enrico L., 2005. A social science research agenda for the disasters of the first century: theoretical, methodological and empirical issues and their professional implementation. 325-96 In: Quarantelli, E.L. (Ed.), What Is a Disaster? New Answers to Old Questions. Routledge, New York, NY.

Quarantelli, Enrico L., 2000. Disaster research. In: Borgatta, Edgar F., Montgomery, Rhonda J.V. (Eds.), Encyclopedia of Sociology. Macmillan, New York, NY, pp. 682-688.

Quarantelli, Enrico L., 1989. Conceptualizing disasters from a sociological perspective. Int. J. Mass Emergencies Disasters 7, 243-251.

Quarantelli, Enrico L., Dynes, Russell R., 1977. Response to social crisis and disaster. Annu. Rev. Sociol. 3 (1), 23-49.

Reuter, Christian, Kaufhold, Marc-André, 2018. Fifteen years of social media in emergencies: a retrospective review and future directions for crisis informatics. J. Contingencies Crisis Manag. 26 (1), 41-57.
Riaz, Muhammad Naveed, Malik, Sadia, Nawaz, Sehrish, Akram Riaz, Muhammad, Batool, Naila, Muhammad Shujaat, Jawwad, 2015. Well-being and post-traumatic stress disorder due to natural and man-made disasters on adults. Pak. J. Med. Res. 54 (1), 25.

Ritchie, Liesel Ashley, 2012. Individual stress, collective trauma, and social capital in the wake of the exxon valdez oil spill. Sociol. Inq. 82 (2), 187-211.

Ritchie, Liesel Ashley, Gill, Duane A., 2010. Fostering resiliency in renewable resource communities: subsistence lifescapes and social capital. In: Rivera, Jason D., Miller, DeMond S. (Eds.), How Ethnically Marginalized Americans Cope with Catastrophic Disasters: Studies in Suffering and Resiliency. Edwin Mellen Press, Lewiston, NY, pp. $51-81$.

Ritchie, Liesel Ashley, Gill, Duane A., Farnham, Courtney N., 2013. Recreancy revisited: beliefs about institutional failure following the exxon valdez oil spill. Soc. Nat. Resour. 26 (6), 655-671.

Ritchie, Liesel A., Gill, Duane A., Long, Michael A., 2018. Mitigating litigating: an examination of psychosocial impacts of compensation processes associated with the 2010 BP deepwater horizon oil spill. In: Risk Analysis.

Ritchie, Liesel Ashley, Gill, Duane A., Steven Picou, J., 2011. The BP disaster as an exxon valdez rerun. Contexts 10 (3), 30-35.

Robertson, Campbell, Krauss, Clifford, 2010. Gulf Spill Is the Largest of its Kind, Scientists Say. The New York Time Aug 2 Retrieved from 2. http://www.nytimes.com/2010/ 08/03/us/03spill.html?_r $=1 \& \mathrm{fta}=\mathrm{y}$.

Roebuck, Julian B., Hickson III., Mark, 1982. The Southern Redneck: A Phenomenological Class Study. Praeger, New York, NY.

Scott, Shaunna L., McSpirit, Stephanie, Hardesty, Sharon, Welch, Robert, 2005. Post disaster interviews with Martin county citizens: 'gray clouds' of blame and distrust. J. Appalach. Stud. 11 (1/2), 7-29.

Sjoberg, Gideon, 1962. Disasters and social change. In: Baker, George W., Chapman, Dwight W. (Eds.), Man and Society in Disaster. Basic Books, New York, NY, pp. 256-284.

Smith, Gavin P., Dennis, Wenger, 2007. Sustainable disaster recovery: operationalizing an existing agenda. In: Havidán, Rodrígues, Quarantelli, Enrico L., Dynes, Russell R. (Eds.), Handbook of Disaster Research. Springer, New York, NY, pp. 234-257.

Smith, Michael D., Krannich, Richard S., Hunter, Lori M., 2001. Growth, decline, stability, and disruption: a longitudinal analysis of social well-being in four Western rural communities. Rural Sociol. 66 (3), 425-450.

Smith, Neil, 2006. "There's No such thing as a natural disaster. In: Understanding Katrina: Perspectives from the Social Sciences. Social Science Research Council Retrieved from. http://understandingkatrina.ssrc.org/Smith/.

St John, Craig, Austin, D. Mark, Baba, Yoko, 1986. The question of community attachment revisited. Sociol. Spectr. 6 (4), 411-431.

Tierney, Kathleen, 2006. Social inequality, hazards, and disasters. In: Daniels, Ronald J., Kettl, Donald F., Howard, Kunreuther (Eds.), On Risk and Disaster: Lessons from Hurricane Katrina. University of Pennsylvania, Philadelphia, PA, pp. 109-127.

Tierney, Kathleen, 2012. A bridge to somewhere: William Freudenburg, environmental sociology, and disaster research. J. Environ. Soc. Sci. 2 (1), 58-68.

Tierney, Kathleen, 2014. The Social Roots of Risk: Producing Disasters, Promoting Resilience. University of Stanford Press, Stanford, CA.

U.S. Census Bureau, 2018. Difference between the ACS and the Decennial Census. In: Understanding and Using American Community Survey Data: what All Users Need to Know. U.S. Government Printing Office, Washington, DC, pp. 60-63.

Wallace, Anthony FC., 1956. Human Behavior in Extreme Situations: A Study of the Literature and Suggestions for Further Research. National Research Council, National Academy of Sciences, Washington DC. 